\title{
No weighting for healthy sustainable local planning: \\ Evaluation of a participatory appraisal tool for rationality and inclusivity
}

\author{
As submitted to the: \\ Journal of environmental planning and management
}

\section{Author and corresponding author: Marcus Grant}

WHO Collaborating Centre for Healthy Urban Environments, Department of Planning and Architecture, University of the West of England, Bristol Frenchay Campus Bristol BS16 1QY

E:marcus.grant@uwe.ac.uk

\section{Co-author: Hugh Barton}

WHO Collaborating Centre for Healthy Urban Environments, Department of Planning and Architecture, University of the West of England, Bristol Frenchay Campus

Bristol BS16 1QY

E: hugh.barton@uwe.ac.uk

\section{Acknowledgements}

The authors would like to acknowledge Chris Pleeth, Clarks property director, and Nick Tyrrell and Alan Pearce, from Alder-King property consultants, for having the vision to use the Spectrum technique to underpin their commitment to excellence in the process that led to the IKON development in Street, Somerset. 


\title{
No weighting for healthy sustainable local planning: \\ Evaluation of a participatory appraisal tool for rationality and inclusivity
}

\begin{abstract}
This paper is concerned with the contribution that project, plan and policy appraisal can make to effective decision-making when shaping a built environment that needs to respond to the demands of local voices and also concerns for global sustainability and for population well-being. It argues that effectiveness depends on appraisal processes being both rational, based on sound science, and also inclusive, involving stakeholders and implementers. A particular problem in both respects is the widespread reliance of decision makers on methods that use weighting. Although these give the appearance of validity, authority and objectivity, the paper argues that such methods are not compatible with the key tenets of appraisal and decision-making that can address the challenges of localism, sustainability, health and inclusion. The paper advocates and evaluates a new technique, SPECTRUM, trialled in practice, which has been developed to meet these challenges. Specific attention is paid to its role in the development of the award winning ICON housing scheme in the Houndwood development at Street in Somerset, England.
\end{abstract}

Key words: health impact assessment (HIA), action research, environmental impact assessment (EIA), evaluation methods, sustainability, collaborative appraisal, consensus building, healthy urban planning 


\section{Introduction}

Appraisal usually performs the role of supporting a final decision taken in a more formal political arena (Tonn et al. 2000). Effective decision-making must be based on a project or plan appraisal method that is fit for purpose. This depends on appraisal processes being not only rational, based on sound science, but also inclusive, involving stakeholders and implementers. A particular problem in both respects can be the widespread reliance on the weighting of objectives, especially when working with issues of sustainable development and public health. This can lead to distortion and bias in the appraisal process and can demand specialist technical approaches that often distance key stakeholders from the heart of the process. To meet these challenges, within the context of supporting health and sustainable development in built environment policy and development proposals, the use of grading without weighting needs further attention. This paper evaluates a tool being trialled in the UK and Europe, which has been developed for this purpose.

The effectiveness of decision-making cannot be judged in a vacuum. The judgment in focus is whether the outcome makes a contribution to a more sustainable and healthier urban environment. Sustainable development and public health are arguably two mutually supportive and ascendant policy objectives in local urban planning in the UK (CLG 2011). In Europe these twin objectives, which saw their heyday in the late 1990s (WHO 1997a and 1997b), are now again on the rise (EEA 2006, EEA 2009, WHO 2009). Given this policy context, we think it timely to reassess whether the appropriate decision support tools are being used, reviewing both content and process.

The current dominant tool for the appraisal of major development projects is Environmental Impact Analysis (EIA). The main assessment of plans is Strategic Environmental Assessment (SEA) across the EU and Sustainability Appraisal (SA) incorporating SEA in the UK. Other tools supplement these standard and regulated processes of appraisal. These include equality assessment, social impact assessment and health impact assessment (HIA), as well as economic, market and transport appraisals. These tools may overlap in their concerns and be pursued at the same time, potentially causing confusion and extra expense (LUC and RTPI 2008). Since the primary purpose of appraisal is to improve the 'soundness' of decision-making by providing reasoned evidence-based evaluation of policy or proposed developments, these inadequacies point to the need for review. However, the focus of this paper is not on policy, or comparing different standard techniques. We examine how the weighting and associated scoring and consolidation of numeric results can distort the primary purpose of sound decision-making, both by failing to deal equitably with the full range of sustainability and health issues, and by the exclusion of non-statutory consultees, especially local interests. We demonstrate how a developing approach, which uses grading in the context of thresholds instead of weighting and scoring, called SPECTRUM, can achieve both stakeholder inclusivity and rationality and support sound planning in statutory or non-statutory processes. Following a brief review of the planning context in the UK, the initial argument falls into the following sections: 
i. a discussion of what is required for decision-making for sustainability and health, derived from a brief review of the rational planning process and the role of participation;

ii. an outline of how appraisal with participation can lead to better decisions, leading to the development of four critical criteria; and,

iii. an explanation of how the use of weighting in appraisal methods can act both against inclusion and rationality leading to an examination of the value a threshold based approach can have.

The second part of the paper is concerned with a threshold based appraisal tool, the SPECTRUM approach. This developing tool is applicable to many kinds of appraisal, and is designed to deliver both effective participation and rational decision support. It is relevant to the scoping of issues and the integrated assessment of proposals or plans. At the WHO Collaborating Centre for Healthy Urban Environments, we have been actively developing and testing SPECTRUM in a range of real and virtual contexts; since 2004 the tool has been led seven times in practice by ourselves, in addition to processes led by several third party users. It has been developed for situations where sustainable development and health and well-being are aspirations against which proposals or policies need to be assessed. In this paper, the work on the Houndwood/ICON scheme in Somerset, England, is examined as an example of the most extended and in depth use of SPECTRUM. The concluding sections compare and discuss the SPECTRUM process in relation to an idealised approach based on the four criteria developed earlier in the paper.

\section{The planning context}

During the ten years in which SPECTRUM has been developing, there have been many changes to the statutory planning system. In 2004, the UK government introduced the concept of 'spatial planning' into the planning system in England and Wales through the Planning and Compulsory Purchase Act. Spatial planning, as an approach to the governance of territorial development, has a long history in Europe (Nadin 2007) and the 2004 Act viewed it as an important arm in the delivery of sustainable development. Distinct from traditional land use planning, spatial planning elevates the role, within planning processes, of all sectoral policies and agencies with a territorial impact. Integration is central to the approach. All agencies that effect change on a spatial territory (private and voluntary sectors as well as local and central state) should cooperate and agree a spatial strategy, working towards a common shared goal (Allmendinger and Haughton 2007). Integration as a key principle of spatial planning was quickly identified by the profession, such as in this following statement from the UK Planning Officers’ Society.

'Spatial planning is, of course, more than 'old style' planning without the previous limitation to land use. It is about an integrated strategy for the future of an area which is rooted in a clear vision, with commitment by all the relevant agencies to its delivery.'

(POS 2005) 
However, advocates of spatial planning must not just assume that spatial planning, if undertaken in an open, transparent, and collaborative way, will inherently lead to consensus and, ultimately, better development. In practice, this is not necessarily the case (Allmendinger and Haughton 2009). Without careful attention to process, the necessary collaboration may not happen and integration can fail. Factors linked to a failure in integration include: a failure to take account of neighbouring communities; a lack of linkage between plans and investment; and the inability to provide processes which engage effectively with communities (Goodstadt 2009).

In England and Wales, the municipality's engagement with communities is obligatory in a process by which the Local Strategic Partnerships lead the development and sharing of a vision expressed within a 'Sustainable Community Strategy'. The instruments of local planning then have the task of gelling rhetoric and principle into sound planning policies on the ground through a suite of local documents referred to as the Local Development Framework.

The UK Coalition government, coming into power in 2010, has given a sharp new twist to this process in a new planning act, the Localism Act 2011. The principle of 'localism' means that the local community (through the medium of parish, town and neighbourhood councils) becomes central rather than peripheral to decision-making. The changes being introduced also involve the preparation of a single National Planning Policy Framework (NPPF) to replace a plethora of thematic planning policy documents. But strong doubts need to be raised on both counts, rationality and inclusiveness, in terms of the outcomes that will actually emerge from the legislative changes.

\section{Content and process}

In attempting to shed new light on appraisal techniques, this paper focuses on the interplay between two fundamental issues - content and process. It is argued that these need re-examination if local planning is to address critical thinking and inclusive working.

The content issue can be summed in the two concerns; sustainable development and health and well-being. In the UK, sustainable development is a frequently stated goal of the statutory planning system (HMG 2004, Wong and Watkins 2009). This has statutory underpinning in section 39 of the Planning and Compulsory Purchase Act 2004 (HMG 2004). The UK government's definition of sustainable development, developed by the Sustainable Development Commission, is now explicitly subscribed to by a range of relevant departments (DEFRA 2011). It amounts to a statement of five principles: to live within environmental limits; achieve a just society; and to do so by means of sustainable economy, good governance, and sound science (DEFRA 2005). Health, on the other hand, is not so deeply embedded in planning legislation, but the importance of planning a healthy environment is increasingly promoted by health agencies (DH 2007, NICE 2008). A UN protocol recently acknowledged that public health should be given a more important role in SEA (Posas 2011). There is plenty of evidence that despite development planning and planning policy using forms of sustainability appraisal, which should in theory help deliver both sustainability and human health, we are still 
waiting for healthy sustainable planning (Barton et al. 2011, Strategic Solutions 2010). It looks like the NPPF (CLG 2011) will be supportive of moves towards incorporating public health as a goal for built development. Analysis of the consultation draft of this document indicates that there is a strong and explicit articulation of 'public health' as an underlying value in the planning system.

The process issue stems from the nature of the content agenda and the recognition that healthy sustainable development needs to rely on multi-dimensional integration across many agencies and at many levels. In some quarters it is readily acknowledged that participation and inclusion are vital for sustainable development (Thomson et al. 2009). However, a comprehensive review of sustainability assessment tools for planning in 13 countries (Poston et al. 2010) hardly touches on participation even as an issue. In contrast, many authors commenting on sustainable development concur that more attention needs to be given to participation and the local level (Devuyst 2000). In a similar vein Cox states "Sustainability is not simply a technical question awaiting an answer" or something to be delivered by experts (Cox et al. 2002 p19). Hersh even talks of a process of 'decision making which [in itself] contributes to the transition to a sustainable society' (Hersh 1999 p395). There have been recurrent calls for the planning system to employ new methods that will challenge well established ways of working and better integrate the evaluation of potential outcomes of planning, for more sustainable development (RCEP 2002, Nadin 2006). What is evident is that the delivery of 'more sustainable development' requires a shift in thinking from isolated sectoral interests towards collaborative working and approaches; cutting across traditional disciplinary, professional and administrative boundaries. This sounds uncannily like a definition of spatial planning itself; a key delivery mechanism for sustainable development according to the 2004 planning act in the UK; indicating a potentially fruitful convergence between content and process.

\begin{tabular}{|l|c|c|}
\hline Why Participation? & $\begin{array}{c}\text { Perspectives in } \\
\text { decision making } \\
\text { theory } \\
\text { (Fiorino 1989) }\end{array}$ & $\begin{array}{c}\text { Perspectives in } \\
\text { planning theory } \\
\text { (Taylor 1998) }\end{array}$ \\
\hline The democratic principle & Normative & Collaborative \\
\hline We will get better appraisals & Substantive & Rationality \\
\hline $\begin{array}{l}\text { We want to demonstrate participation } \\
\text { (to build public trust and credibility) }\end{array}$ & Instrumental & Pragmatic \\
\hline
\end{tabular}

Table 1. Why participation in appraisal processes?

In exploring the reasons for wanting to combine participation within appraisal, three fundamental reasons can be discerned from the literature (Fiorino 1989, Taylor 1998). Firstly, the democratic principle demands this; secondly, that we will get better 
appraisals through doing so; and, thirdly, we will build trust and credibility. These three reasons can be derived from policy and decision-making literature, where they are referred to as normative, substantive and instrumental perspectives respectively. In planning theory, they are referred to as the collaborative, rationale and pragmatic stances (see table 1).

\section{Balancing rationality and inclusivity in appraisal}

Experimental findings indicate that humans are quite bad at making complex unaided decisions (Slovic et al. 1977). What is required is: 'a structured approach that emphasises qualitative guidance for how to think clearly and make smarter choices' (Gregory 2000 p36). Advocacy for a rational planning process in the 1960s and 1970s, focused almost exclusively on systematic evaluation related to specific stages of plan making such as goal making, system analysis, design of alternatives and review (Chapin 1962, McLoughlin 1968, Faludi 1973). There is long track record of development of rational decision support tools for assessing complex problems such as EIA and CostBenefit Analysis (CBA). A large number of techniques, involving various degrees of mathematical computation, were developed especially in the operational research and natural resource management fields (Figueira et al. 2005 and CLG 2009). These types of rational decision support techniques have long been criticised for their:

i) partiality; ignoring evidence from other disciplines (Barker 2008, Stern 2007) and over-reliance on an expert evidence base in the field of sustainability (Brown et al. 2005). The concept of even what constitutes an "evidence-base" is an increasingly contested area (Berger and Luckmann, 1971, Gibbons et al. 1994, Nowotny et al. 2001).

ii) exclusive nature; relying on purely technical exercises which can have a disempowering effect on key local stakeholders, excluding important local knowledge (Forester 1989, Chambers 1994) and not fully supporting the final decision that is taken in a more formal political arena (Tonn et al., 2000).

iii) reductionist stance; and consequent weakness in supporting synergistic solutions (Frasera 2006, Healey 1992)

iv) inherent failure in moving from assessment to implementation (Khakee 1998). This can be pre-conditioned through the 'invisible' products of collaborative processes such as capacity building, developing inter-organisational relationships, building trust and commitment to the delivering the final outcome (Grant 2003 and 2004).

The value and need for inclusive stakeholder approaches has been exhaustively argued (Chambers 1994, Healey 1992, Innes 1998) demonstrating the benefits in terms of quality, agency commitment and organisational capacity (Karkee 1998, Gregory 2000). What is needed is a process combining an evidence-based analysis, with a rationalcritical dialogue (Habermas 1981, Healey 1996) supporting 'an ideal speech situation' (Skollerhorn 1998). Habermas's insight that the growing intervention of formal systems served to obfuscate ideal speech situations seems all too real. With the continual pressures of statutory deadlines and entrenched linear procedures, local authority planners, already playing catch-up with their statutory timelines, can find it difficult to 
focus on perceived extras such as the 'quality of dialogue' (assumed in the theoretical discourses) that should be advising spatial planning praxis. Maybe even the rational approach being driven out in the quest to meet the targets demanded by performance driven management?

In spite of the constant discourse, and hopefully progress, in both understanding and theory; practical and everyday appraisal of development policies and plans seems trapped in something of a time-warp. So what is necessary for building a rationalcritical, but also inclusive, dialogue space? Barton and Grant (2008) posited nine essential attributes that appraisal for local decision-making needs to have, over and above just good appraisal (Table 2).

A set of principles that sustainability and health appraisal processes should try to fulfill.

They need to:

- be explicit about objectives - treating them not only as derived from superior authority or convention but open to debate and scrutiny;

- be holistic in relation to sustainable development - encompassing all the relevant aspects of environmental sustainability, health, social inclusion and economic vitality;

- be inclusive of stakeholders - facilitating the involvement of varied public, private and community interests and inviting and valuing their contribution;

- tap into expertise of all kinds - local, cultural, political, market, specialist, generalist;

- focus attention on key issues - including cumulative and interactive issues, through effective scoping processes, so that resources are allocated wisely and appropriate expertise is used;

- support collaborative learning - enabling the progressive, mutual development of understanding and ideas

- be rational and as rigorous as context allows - analysing problems / opportunities, developing options, testing systematically and honestly against criteria

- support creativity - that helps develop and test options and provides a positive incentive to the professional team and the project initiators to improve the scheme

- build legitimised, well supported decisions - with effective implementation and collaborative action in related fields by other organizations.

(after Barton and Grant 2006)

Table 2. Attributes for appraisal in local sustainability and health decision-making Barton and Grant (2008)

While the process theorists emphasise the planner as mediator between competing interests (Healey 2003), the sustainability and health debates revolve around a planner finding solutions that deliver these outcomes. Tensions ensue, since the desired solutions may not always coincide with initial stakeholder positions. We argue that the planner must hold both of these roles at the same time; the glue being an overarching responsibility for the planner to ensure that rational-critical dialogue is placed centrally in the participatory process.

In conclusion, in light of the demands and complexities brought into the appraisal process by the requirement for both rationality and inclusivity, four critical questions need to be posed: 
How can the inequality of participants (and especially non-participants) in the process be addressed in a defensible manner?

How can the diversity of measuring rods used to assess impact by different participants (for example financial, physical or public acceptability) be accommodated?

How can an evidence-based approach avoid resulting in a narrow reductionism that can also be impermeable to local interests and the local community?

How can conflict resolution and synergistic policy development be supported?

We will return to this list of putative challenges for appraisal later and use them as yardstick to test a new technique, the SPECTRUM approach.

\section{Weighting as the unwelcome guest at the party}

A key factor which influences the degree to which complex problems can be resolved is the way the different interests, with their apparently conflicting priorities, are handled. As discussed above, a participatory and rational approach has particular requirements. Very diverse types of criteria have to be assessed in such a way that the participants can understand and appreciate them all - not just those they favour.

The choice of technique has profound value implications. These will be explored here relying on logical argument. The end point of the argument will be that a threshold approach, rather than a weighting approach, offers by far the most helpful way of achieving inclusive and critical rationality.

Overall, there at least five basic ways of summarising and comparing impacts:

Directional: moving towards or away from each objective, as in the charts commonly used in SA;

Ordinal: the ranking of alternatives in relation to each objective;

Reductive: where impacts on all objectives are reduced to a common unit, such as money in CBA;

Summative: where each objective is weighted, allowing a total score for each alternative or proposal, as in the Code for Sustainable Homes;

Graded: where thresholds of positive or negative impact are assessed for each objective, as for example when environmental standards are applied in EIA.

These different approaches are all part of the toolkit of rational appraisal but differ markedly with regards to inclusivity.

SA in the UK uses the combination of directional and summative approaches in a simple way. The number of assessments of a policy moving towards an objective (ticks, arrows up, or green icons) and away (crosses, arrows down or red icons) are added and combined to give an overall score for a policy or option. In summing the composite outcome there is an implied weighting, in that each objective is treated as equally important. This approach is sometimes termed a 'dominance' approach, since it is easy to judge the dominance between two alternative options (CLG 2009). Decision takers 
can just choose the alternative with more ticks and fewer crosses. However, dominance as an approach is limited, because the objectives that cannot be achieved are too easily side-lined through the weight of the majority. Yet they may be just as important, or more so, than those presumed to be achievable. The dominance approach thus denies two basic principle of sustainable development; that many different goals should all be achieved (at it simplest - economic, environmental and social goals all need to be achieved - one should not be sacrificed to another); and that synergistic solutions must be sought. There is a further concern; simple scoring (+, ?, 0 or -) and summation belie the complexity of the assessment. There is no sense in the overview charts of the degree to which something is being achieved, or the level of uncertainty about that achievement. So one objective may be compromised or sacrificed on the altar of another objective, where success is more about hope than certainty.

Summative approaches are also represented by project assessment methods with widespread credence in the UK; BREEAM and the related Code for Sustainable Homes. These both cover sustainability criteria and adopt fixed weighting schemes. In so doing they are similar to contemporary processes such as the Comprehensive Project Appraisal advocated by the Royal Institution of Chartered Surveyors (RPA 2000). These weighting methods provide a ready way of trading-off a good result for one criteria against a bad result for another. However, it is problematic to assume that there even can be a 'trade-off' between any two particular criteria. The reduction of all factors to a common denominator is also problematic in itself, as a consequent suppression of low weighted factors. In spatial planning, CBA is increasingly being replaced by MultiCriteria Analysis (MCA) (Munda 2005). MCA attempts to overcome the limitation of pre-fixed weights and is emerging as a popular more inclusive rational approach for supporting multi-stakeholder environmental decisions (Hajkowicz, S., 2008). In standard MCA assessments the weighting is explicit and used to present a summative score. The weighting reflects the values assigned to criteria by those involved, the weights may then be varied in sensitivity tests. Such MCA techniques have been designed to help overcome the limitations of making a judgment in complex situations through imposing a disciplined structure on the way in which data is recorded, presented and judged (Bazerman 1998). The fields of science in which MCA arose, management theory and traditional economics, have left a methodological legacy with specific problems when dealing with sustainability and health as content (Munda 2008).

Neither of these fields function well when there are many (often-non monetary) externalities and a mixture of qualitative and quantitative data. The perceived need for weighting is led by notions of 'weighing-up competing interests' or 'ensuring different criteria can be balanced against each other' and the call for the outcome to be expressed as a single score. These are laudable ambitions for analysis of a complicated problem (i.e. one which yields to systematic evaluation of many independent elements), but sustainable development and public health present complexity. In dealing with complex problems (Rittle and Webber 1973), weighting can be counterproductive. Weighting places a reliance on 'alternatives-focussed' thinking, this can lead the participants to expedient shortcuts in order to get to a rapid solution, not usually the best (Gregory 
2000). Health and sustainability both demand 'values-focussed' thinking. Some researchers have found that weighting based techniques can even alienate the decision makers and experts in multi-stakeholder problems due to their 'black box' nature (Bojo'rquez-Tapia et al., 2005). The problems with weighting have been illustrated in a critical review by Hämäläinen and Alaja (2008). They list ways in which biases and errors can creep into these types of decision analyses including 'problems regarding the analyst's role', 'procedural mistakes when eliciting weights', 'interpretation of criteria weights' and several other methodologically problematic phenomena.

Weighting schemes do have the advantage of approachability. Stakeholders can become deeply engaged in the arguments about which criteria are most important. When the resultant scores are summed, they also deliver an overall 'answer' at the end. But they suffer from a fundamental logical fallacy, and one that strikes against the heart of appraisal and decision for sustainable development and public health. Namely, that in a context where many disparate goals need to be met, weighting objectives (when combined with a common unit of measure that is then summed) results in pitching one goal against another. The underlying message is not only that multiple trade-offs can be made, but that they should be made. This attempt to reduce all criteria to a common means of exchange (whether money or weights) belies the uniqueness of each criterion. For example, as a criterion 'urban design quality' is not in any sense equivalent to 'safety from flood'. It is not valid to substitute flood risk for beauty, or visa versa. Both aspects will have thresholds of unacceptability and both need to be valued for themselves. Importantly, showing the grade of each unique criterion best supports the consideration of potentially interactive outcomes, either positive or negative.

\begin{tabular}{|l|l|}
\hline Why Participation? & The problems with weighting \\
\hline The democratic principle & $\begin{array}{l}\text { Allows the power dynamic to be easily concealed acting } \\
\text { against the trust needed for true collaboration. }\end{array}$ \\
\hline $\begin{array}{l}\text { We will get better } \\
\text { appraisals }\end{array}$ & $\begin{array}{l}\text { Scoring each objective separately leads to summing the } \\
\text { whole and reduces the incentive to search for synergistic } \\
\text { gains. }\end{array}$ \\
\hline $\begin{array}{l}\text { We want to demonstrate } \\
\text { participation }\end{array}$ & $\begin{array}{l}\text { Weighting is often carried out in an atmosphere of } \\
\text { expert knowledge creating a 'black box' that diminishes } \\
\text { trust and ownership in the final decision. }\end{array}$ \\
\hline
\end{tabular}

Table 3. Problems with weighting in participatory appraisal processes

In summarising the above discussion, weighting presents a problem for all three reasons identified earlier in the paper for the importance of participation (see table 3). In terms of the democratic principle, weighting allows the power dynamic to be easily concealed, acting against the trust needed for collaboration and transparency. Weighting reduces the incentive to link objectives together in a search for synergy, finding a single solution to solve a range of issues. In terms of a demonstration of trust, weighting is often 
carried out in an atmosphere of expert knowledge creating a 'black box' that diminishes trust and ownership of the final decision.

\section{Problems of weighting: an example drawn from practice}

The problems of weighting can be illustrated by an example. Part of the evidence base for the Local Plans around Lincoln, on the East Coast of England, feeding into the appraisal, was a comparison of potential housing sites. They were assessed against a number of sustainability criteria. Some of the typical criteria are listed below with their weighting:

Location grading: city core - urban periphery - outlying settlement 6

Greenfield/brownfield (the latter gets the full value) 10

Access to a bus route, existing or potential 2

Access to town or district centre $\quad 2$

Availability of attachment to main water supply 1

Protected landscape/ecology $\quad 1$

Flood risk (no risk gets 10) 10

It is immediately apparent that the issues considered most important - avoiding greenfield development and avoiding flood risk - will dominate the outcome. Those who value high landscape or ecological quality will find their views submerged. Sites will be selected - and were - that are not accessible to facilities or regular public transport.

The weighting also affects the degree to which discriminating judgements about impact are possible. Large weights permit a range of degrees of impact, while small weights may simply be positive/negative and leave little room for critical thresholds of impact to be reflected or properly taken into account. For example mains water supply for major sites is rarely as simple as yes/no. There will be thresholds of demand that can be managed with existing systems, and subsequent investment thresholds that justify a lower site value, or there could be fundamental supply problems. Equivalently there might be spare capacity that represents real development potential. The same applies to many other aspects of infrastructure.

Criteria can also be added or taken away. In the first version of the assessment, presented at a Local Public Inquiry, flood risk was omitted. Instead it was treated as a subsequent test, once sites were provisionally chosen. This affected the site selection profoundly.

FIGURE 1. Problems of weighting: an example drawn from practice 
The example from practice (Figure 1) illustrates some other limitations of weighting. There is often a degree of arbitrariness in the list of criteria and the weights ascribed, and this affects the outcome.

There will always be different views about the appropriate weights, and therefore the process risks alienating those who feel side-lined.

Small weights effectively reduce the potential for discriminating judgements about impact levels.

Critical thresholds of impact, with significant health, sustainability or cost implications, will often be unrepresented.

\section{The value of grading and threshold based approaches}

MCA does not need to involve weighting. SPECTRUM appraisal falls into a category referred to as a 'non-compensatory' MCA method (CLG 2009). Such methods do not provide a ready way of trading-off a good result for one criterion against a bad result for another, which as we have already discussed as problematic. An alternative way of summarising and comparing impacts is a 'threshold' approach. This is commonly used in EIA, where for example air quality standards, or levels of impact on rare habitats, provide criteria for project assessment. Thresholds may be derived from statutory policies, local plan policies or from professional and stakeholder judgement. There are grades of impact: some may be open to 'mitigation' measures; others may be considered unacceptable. In other words, at the extreme criteria may be critically important, while normally they are not. Air quality is just such a case. If the quality is predicted to fall below a certain level, then development may be unacceptable, irrespective of other potential benefits.

These methods hark back to 'threshold theory' developed in the 1960s for new settlement planning in Poland (Malisz 1972) and during implementation in the UK and Ireland (Kozlowski et al. 1972). Settlement development potential was seen to be related to spare capacity in infrastructure. A critical threshold was reached if major investment (in roads, sewage, schools etc.) was needed to provide for growth. Three types of threshold are encountered: limits based on topography; limits based on infrastructure technology and limits based on the impact of growth on the nature of urban form itself (such as thresholds in terms of how far people are prepared to walk to facilities). This final category of threshold can be of particular value in designing for healthy lifestyles or sustainable transport systems. Threshold theory relates well to that of 'carrying capacity' often found in nature conservation planning; an ecosystem can maintain its life-support capabilities with a certain amount of disturbance, pollution or invasion, but once this passes a particular threshold, the carrying capacity (i.e. its functionality and integrity) will be irreparably damaged leading to collapse. There is no valid rationale for any trade-off at these limits. One advantage of a threshold approach is that it directly relates the level and seriousness of the impact to its importance. At the same time it can identify where action is needed to mitigate impacts. To follow the previous example, where air quality is predicted to be sub-optimal (but not critical), a 
threshold level requiring mitigation measures can be defined. So the appraisal process is more than a retrospective evaluation, it is action oriented. It neatly ties together evaluation with project development; as such it focuses attention where it is needed.

EIA and the early threshold methods, however, suffer from being used as expert processes, involving consultation with specific agencies with minimal attempt at inclusive decision-making. Yet the avoidance of potentially divisive weighting schemes can open the door to participation by diverse stakeholders. Kozlowksi and Hill (1993) refer to the threshold approach as opening up a 'solution space' that provides a platform for 'interdisciplinary' and 'multi-level' co-operation. As such with SPECTRUM sensitivity (the final balance to be struck between criteria in supporting a decision) is kept open during the whole process. The sensitivity analysis stage has been found to be a fundamental element in attaining consensus among members of interdisciplinary teams and for settling debates in controversial projects (Bojorquez-Tapia et al. 2005).

This is exactly what the SPECTRUM approach was hoping to achieve when it was devised: both a rational, evidence-based yet creative process; and also one which facilitates inclusivity and stakeholder engagement, drawing on the distinctive concerns and knowledge of different groups, and building momentum for concerted decisions and action. The following sections describe the SPECTRUM process and assess whether these aspirations have been realised.

\section{SPECTRUM appraisal}

In terms of the preceding discussion, SPECTRUM is a form of participatory noncompensatory threshold appraisal. SPECTRUM is expressly designed to recognise the integrated agendas of the wider determinants of health and sustainable development, the need for a transparent rational process and the need for an inclusive communicative process. SPECTRUM has been developed through iterations between practice and reflection over the past nine years by the WHO Collaborating Centre for Healthy Urban Environment, Bristol.

\section{The development of SPECTRUM appraisal}

The technique has its origins in environmental capacity assessment. It was a reaction to the prevailing techniques of the time that took the view of the environment as being a constraint on development rather than an asset to be valued (Barton 1995). Initially, the technique was adapted for use by the Environment Agency under the heading Sustainability Threshold Assessment (Carroll et al 2002). Subsequent refinements include clarifying the process for determining local social, health and economic criteria and codifying the process of stakeholder involvement (Barton and Grant 2008).

'SPECTRUM' as a name has been chosen as it reflects three key features of the technique: the whole gamut of sustainable development and health criteria; the involvement of diverse stakeholders, often with contrasting views; and the use of a colour spectrum as a means of presentation. As a tool it is capable of framing and 
facilitating a creative assessment processes in which participants can contribute to a 'better' project, policy or plan. It does this through:

i). facilitating effective stakeholder involvement in appraisal;

ii). supporting mutual learning and triggering new ideas or options;

iii). focusing attention on key issues or areas of uncertainty where more design work, investigation or appraisal is needed ('scoping'); and

iv). enabling an overview to be taken of the merits of a proposed project, policy or plan - including both the positive and the negative features.

\begin{tabular}{|c|c|c|c|}
\hline Grade & Level & Test & Example: in relation to water \\
\hline BLUE & $\begin{array}{l}\text { an excellent } \\
\text { level:- }\end{array}$ & $\begin{array}{l}\text { the criterion is fully } \\
\text { satisfied. }\end{array}$ & $\begin{array}{l}\text { You might expect autonomy of } \\
\text { supply and treatment, with in } \\
\text { situ drainage and flood risk } \\
\text { effectively managed. }\end{array}$ \\
\hline GREEN & a good level:- & $\begin{array}{l}\text { the criterion is generally } \\
\text { well satisfied, at least to } \\
\text { the level we would } \\
\text { currently consider best } \\
\text { practice. }\end{array}$ & $\begin{array}{l}\text { There would be demand } \\
\text { management, rain water and/or } \\
\text { recycled grey water for low } \\
\text { grade uses, sustainable drainage } \\
\text { systems and effective flood risk } \\
\text { management, but not full water } \\
\text { autonomy. }\end{array}$ \\
\hline YELLOW & $\begin{array}{l}\text { a negotiable } \\
\text { level:- }\end{array}$ & $\begin{array}{l}\text { There are significant areas } \\
\text { of unsustainable or } \\
\text { unhealthy practice that } \\
\text { could (at least in theory) } \\
\text { be overcome by } \\
\text { practicable means. }\end{array}$ & $\begin{array}{l}\text { It might be the absence of any } \\
\text { serious strategy of minimising } \\
\text { demand or reusing grey water. }\end{array}$ \\
\hline ORANGE & $\begin{array}{l}\text { a highly } \\
\text { problematic } \\
\text { level:- }\end{array}$ & $\begin{array}{l}\text { the criterion is not likely to } \\
\text { be satisfactory fulfilled } \\
\text { without major } \\
\text { reassessment, a change in } \\
\text { the basic development } \\
\text { assumptions, or action in a } \\
\text { related (but independent) } \\
\text { decision area. }\end{array}$ & $\begin{array}{l}\text { The assessment might be orange } \\
\text { if development was proposed in } \\
\text { an area of water shortage. }\end{array}$ \\
\hline RED & $\begin{array}{l}\text { an } \\
\text { unacceptable } \\
\text { level:- }\end{array}$ & $\begin{array}{l}\text { the criterion cannot be } \\
\text { satisfied, either the site or } \\
\text { the brief must be changed. }\end{array}$ & $\begin{array}{l}\text { This might apply where } \\
\text { development is proposed in a } \\
\text { major flood plain. }\end{array}$ \\
\hline
\end{tabular}

Table 4. The five level grading scheme used in Spectrum appraisal. 
SPECTRUM uses a five level threshold grading scheme for each criteria under consideration (table 4). These grades are more than simply better or worse. They each have specific implications for subsequent work. A RED grade for a criterion implies the impact is such that the project or policy is unacceptable as it stands and requires a fundamental rethink. Thus failure in relation to just one criterion can, at the extreme, condemn the whole proposal or plan. In this aspect SPECTRUM is very different from weighted systems where one failure can be submerged within an overall score. At the other extreme a BLUE grade for any specific criterion indicates that the proposal is outstanding. GREEN indicates that it is satisfactory. YELLOW indicates that the intentions are fine, but there is work to be done before there is any guarantee of success. ORANGE indicates that that while there is the theoretical possibility of the proposal being satisfactory, it is difficult to see how this can be achieved in practice. The distinctions can be illustrated with the example of a new housing development in the flood plain. A yellow would be appropriate if effective alternative storage for floodwater was thought to be feasible, and even if not yet designed, could be implemented by the developer; an orange would be appropriate if, while alternative storage was a possibility, it would rely on another landowner who would need a lot of persuasion. A red would be given if there was no way to mitigate the flood problem. Thus the grading process gives strong indications about the way forward.

As will be shown in the case study that follows, the identification of the criteria and subsequent debate about them are absolutely central to the technique. The manager of the process has the task to ensure all interests, including non-present stakeholders and future generations are appropriately represented by the list of criteria and then that those present accept the final list after discussion. The technique relies on a step by step rational process open to evidence based thresholds being determined for the identified criteria. It involves a twin track approach of having expert input, and guidance of process and content, running in parallel with a participatory process of engagement and debate. The case study, as with all SPECTRUM applications, demonstrated the following six discernible phases (figure 2, after Barton and Grant 2006).

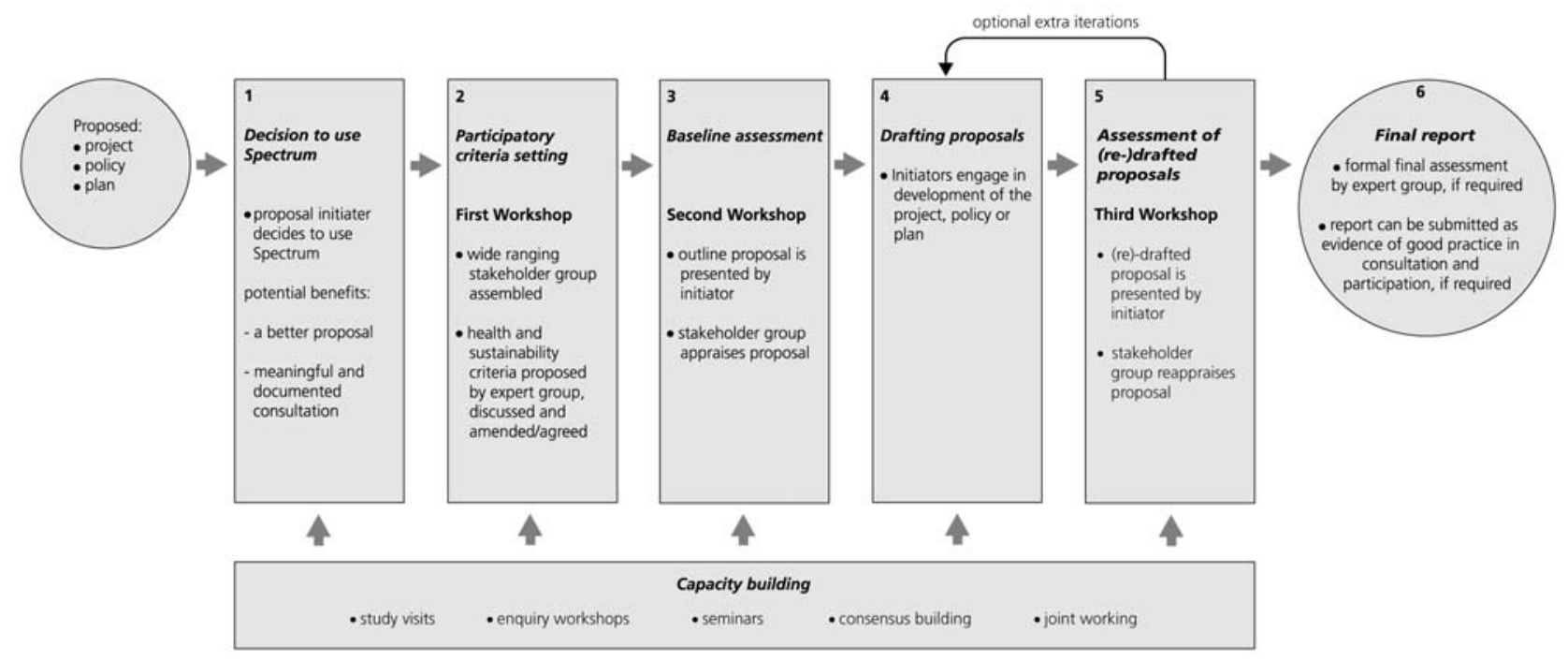

Figure 2. The six-stages of the SPECTRUM process 


\section{SPECTRUM appraisal in practice}

SPECTRUM has been used, by the WHO Collaborating Centre, with a range of planning instruments including policy, plans and proposals, often developing extra dimensions to the tool. These include two major project appraisals in South West England, a review of housing policy for Merthyr Tydfil County Borough Council, a Welsh authority; and a major area-wide regeneration proposal and a housing strategy appraisal with Bristol City Council. It has also been used in a wide range of training projects and health impact appraisal within the WHO European Healthy City network (see table 5). It is useful to examine its use at a 12ha housing site, the Houndwood development (known as ICON) in Street, the county of Somerset in southwest England, this represents the most prolonged use of the tool.

At Houndwood, the existing site use was warehousing for Clarks Shoes national shoe distribution operation. These warehouses were to be demolished. Outline planning permission was granted in January 2004 for residential development, subject to a number of conditions. The landowner, Clarks, had stipulated that the housing development should follow highly sustainable development principles. Clarks would control the development through production of a design brief to be adopted by the local planning authority (Mendip District Council) as Supplementary Planning Guidance, and by exercising strict control over the sale of land. SPECTRUM was chosen as the instrument through which a participatory process would deliver an agreement about what 'sustainable development' entailed, appraise the proposal and enable fidelity to the design principles as the project proceeded. Initial appraisal work during 2004 underpinned site planning and resulted in a design brief for the development. In 2006, this was followed by an appraisal of the masterplan as developed by the architects, Feilden Clegg Bradley, and subsequently appraisal of phase one details (of three development phases) for what was later called the ICON housing scheme.

At the start the expert team, facilitating the process, led the development of a list of 22 draft criteria for consideration by all participants under the following headings: Global ecology, Natural capital, Social provision, Access and movement, Local environment, Economic capital, and Processes. As this was a residential housing site the criteria emphasised issues such as affordability, social facilities, access and movement and quality in the public realm, safety and privacy. Fundamental issues of carbon reduction, biodiversity, social inclusion and walkability were also represented. The methods for measuring each criterion were made distinct and explicit, so that assessment against grades was clear to all. The criteria were first aired at an open public meeting in April 2004, they were left open and subject to comment by stakeholders for a six-week period. Through subsequent discussions, and sub-divisions within criteria the draft set of 22 criteria were developed into a final set of 28. At the open meeting, local residents, who lived in three areas abutting the site, selected two representatives from each area to join what was then termed the core stakeholder group. 


\begin{tabular}{|c|c|c|c|}
\hline $\begin{array}{l}\text { SPECTRUM } \\
\text { process }\end{array}$ & Type & $\begin{array}{l}\text { Start } \\
\text { date }\end{array}$ & Innovation \\
\hline $\begin{array}{l}\text { Morlands, } \\
\text { Glastonbury }\end{array}$ & $\begin{array}{l}\text { Mixed use } \\
\text { regeneration on town } \\
\text { edge site, } 34 \mathrm{ha}\end{array}$ & 2002 & $\begin{array}{l}\text { Using appraisal criteria to } \\
\text { develop supplementary } \\
\text { planning guidance }\end{array}$ \\
\hline $\begin{array}{l}\text { Houndwood, } \\
\text { Street } \\
\text { Design brief }\end{array}$ & $\begin{array}{l}\text { Housing } \\
\text { development in rural } \\
\text { town, 12ha, 400units }\end{array}$ & 2004 & $\begin{array}{l}\text { Using appraisal criteria to } \\
\text { underpin planning conditions }\end{array}$ \\
\hline $\begin{array}{l}\text { Houndwood, } \\
\text { Street } \\
\text { Masterplan }\end{array}$ & $\begin{array}{l}\text { Housing } \\
\text { development in rural } \\
\text { town, } 12 \text { ha, } 400 \\
\text { units }\end{array}$ & 2006 & $\begin{array}{l}\text { Revisit and update of the design } \\
\text { brief criteria following } \\
\text { appointment of architects to } \\
\text { guide future phases }\end{array}$ \\
\hline $\begin{array}{l}\text { Houndwood, } \\
\text { Street } \\
\text { Phase } 1 \text { IKON - }\end{array}$ & $\begin{array}{l}\text { Housing } \\
\text { development in rural } \\
\text { town, 4ha, } 138 \text { units }\end{array}$ & 2006 & $\begin{array}{l}\text { Drawing down masterplan } \\
\text { criteria into scheme housing } \\
\text { design criteria }\end{array}$ \\
\hline Merthyr Tydfil & Housing Policy & 2006 & $\begin{array}{l}\text { Adaptation to include input } \\
\text { from elected members } \\
\text { Including more explicit linkage } \\
\text { to the wider determinants of } \\
\text { health }\end{array}$ \\
\hline $\begin{array}{l}\text { Bristol City } \\
\text { Council }\end{array}$ & Housing Strategy & 2009 & $\begin{array}{l}\text { Application as rapid appraisal } \\
\text { at expert workshop }\end{array}$ \\
\hline $\begin{array}{l}\text { Knowle West, } \\
\text { Bristol } \\
\text { Partnership }\end{array}$ & $\begin{array}{l}\text { Mixed use urban } \\
\text { regeneration area } \\
\text { with many local } \\
\text { stakeholders }\end{array}$ & 2010 & $\begin{array}{l}\text { Explicit recognition of impact } \\
\text { on health inequality added to all } \\
\text { criteria }\end{array}$ \\
\hline $\begin{array}{l}\text { Westmorland } \\
\text { House, NHS } \\
\text { Bristol }\end{array}$ & $\begin{array}{l}\text { Major inner city } \\
\text { residential } \\
\text { redevelopment } \\
\text { proposal }\end{array}$ & 2011 & $\begin{array}{l}\text { Addressing wider determinants } \\
\text { of health in development } \\
\text { management, a desktop study }\end{array}$ \\
\hline $\begin{array}{l}\text { South } \\
\text { Gloucestershire }\end{array}$ & $\begin{array}{l}\text { Proposed town } \\
\text { extension with } \\
\text { several local } \\
\text { stakeholders }\end{array}$ & 2011 & $\begin{array}{l}\text { Process being run at arms } \\
\text { length by primary care trust } \\
\text { team and local authority. }\end{array}$ \\
\hline $\begin{array}{l}\text { Bristol City } \\
\text { Council }\end{array}$ & $\begin{array}{l}\text { Large } \\
\text { interdisciplinary } \\
\text { expert group } \\
\text { appraising draft } \\
\text { planning policies }\end{array}$ & 2012 & $\begin{array}{l}\text { Adapted to feed into statutory } \\
\text { plan consultation }\end{array}$ \\
\hline
\end{tabular}

Table $5 . \quad$ SPECTRUM processes led by the WHO Collaborating Centre for Healthy Urban Environments 
In addition to these local representatives, and the usual council and agency representatives, the group included a local head teacher and the East Somerset Police District Architectural Liaison Officer, and representatives from Street Society, Street Neighbourhood Watch Association, Somerset Trust for Sustainable Development and Street Parish Council. The core stakeholder group together with the client and consultant team led to a core stakeholder group of some 25 people.

During Summer 2004, capacity raising for the whole group was embarked on. This started in May with a design workshop where a hands-on layout exercise helped stakeholders explore constraints and opportunities. This was designed to quickly identify issues that might lead to disputes or polarised debate. Capacity raising continued with two site visit days to exemplary schemes. Through Autumn and Winter, a draft scheme was drawn-up and subject to a public exhibition. In March 2005, the scheme was graded by the core stakeholder group at an evening event. Two sub-groups graded the previously established criteria and explored issues in detail. Then, in plenary, participants, having first heard a report of the sub-group discussions and grades, were invited to record their own grade. Differences in grades, especially where striking, were focussed on to stimulate further dialogue. This lead on occasion to a criterion being reclarified, to new information coming to light, or to a better understanding of the changes required to improve a grade. All participants' grades were recorded; conveying a clear indication of where there was still disagreement. Pertinent comments about how to improve the grade were always sought. In the final report, independent grading and commentary from the WHO expert team was also recorded alongside that of individuals and sub-groups.

In the early summer of April 2005, the designers developed a final masterplan for outline planning permission taking note of the grades and comments. As this stage neared completion, design development was influenced through iterative information exchanges, almost weekly during some periods, between architects and with the expert WHO team, so as to achieve a better final grade. In autumn 2006, as a separate process, the design of the first phase was evaluated and improved using SPECTRUM. This appraisal was conducted at a specially convened design team meeting and supported by desktop studies and led to a submission to the local planning authority for detailed planning permission.

\section{Assessment of SPECTRUM}

The case study above, as well as our broader experience of the technique, allows some generalisations. Firstly, there is the issue of how SPECTRUM fits into the more general planning process. Its considerable advantage is that, being outside any statute, it can be adapted to many different situations. It can be applied as a one-off workshop to try to resolve a specific problem or integrated into the formal processes with a series of events and back-up work. In the case of both Morlands and Houndwood, SPECTRUM complemented and made use of other studies, including an EIA and a transport study. It provided a developing agenda for the land owners, designers and developers. With Houndwood, the report emerging from it was subsequently presented to the local 
authority in satisfaction of SA and satisfaction of participation requirements. The SPECTRUM grading ran through development process from a blank drawing board to the detailed design. It kept the agreed and desirable outcomes visible for all participants at all times. Together with a committed landowner and a skilled architectural design team, it helped retain focus on creative and synergistic responses to problems and making detailed decisions within an agreed explicit holistic framework.

The absence of weighting has in all cases been critical to inclusivity by establishing a valuable rapport between participants in the process. Each criterion is valued for itself, so people do not feel excluded because of low weighting of their interests or beliefs. Each individual, by submitting their grade, can demonstrably make a mark on the proceedings. It is also axiomatic that the different interests at local and strategic scales need to perceive that they are valued as an integral part of the decision-making process (Habermas 1984). At the same time they learn that other's interests need to be recognised. For example, a developer will (in our experience) accept that ecology is important for itself, not simply to get planning permission, while a local ecology group will recognise that the developer has to make a profit.

Once the criteria list is accepted, it is normally possible to get some agreement on the degree to which criteria are satisfied, and ascribe grades. Where there is disagreement, this is used to enliven discussion. Frequently, new facts or knowledge emerge during this discussion, which can alter perceptions and grades. There are also examples of new information or strong opinions coming to light during the process, and being recorded in such a way as to have profound influence on the design. The technique makes full value of having diverse experts and lay stakeholders around the table (including the distinctive knowledge of those living locally).

The real difficulties of the process do, however, need recognition. First is the issue of stakeholder attendance. It is vital that key players are there to inform and listen and debate. When, in the case of a development proposal, the developer or the designer are absent, or the local planning department is not there when reviewing a plan, then the value of the process is greatly reduced. The process becomes stillborn, lacking the opportunity for creative dialogue. Even though SPECTRUM is not a formal obligation, it needs to be integrated into the overall development or policy process if it is to realise its full value.

Another critical factor is the level of expertise of the SPECTRUM managers. This is in relation to both technical and political insight. The initial list of criteria, and later judgements about impact, rely on sound experience. The selection of thresholds, for example, needs to be informed by the evidence base. The workshops require careful facilitation to ensure critical thought, inclusive discussion and, most importantly, clear outcomes are agreed. McGuirk (2001) in reviewing three cases of practical participatory planning processes provides a useful critique of communicative based approaches. He argues that often they have not acknowledged the 'irreducible nature of power and difference' (McGuirk 2001, p1). Whilst agreeing with this standpoint, Grant and Barton have found in SPECTRUM, the open nature of discussions, between those with the 
power and final say and other less powerful stakeholders, at least meets the conditions of exposing the dynamic. This itself can support a constructive dialogue within the overall unequal discourse.

SPECTRUM is certainly not a panacea for all situations but it is ideally suited to early stages and iterative improvement of a proposed plan or policy. From their first experiences, practitioners such as Kozlowski (1972) recognised that this type of analysis can play an important role in;

- formulating the basis for decision-making;

- evolving feedback mechanisms;

- supplying information for planning synthesis; and

- integrating qualitative and quantitative methods.

SPECTRUM displays these characteristics and may have been a necessary contributor to success in the ICON development at Houndwood, but it was not sufficient in itself. The tool was only brought into play through high-level commitment to the sustainability goals by the landowner, client and planning authority. Through this commitment, planning and architectural teams were chosen whom also had skills and experience needed for the project. SPECTRUM was able to capture these high-level aims; provide a focus for the professional teams; and offer a constructive and open process that supported goodwill and understanding through the entire stakeholder body.

A tangential indicator of a successful final outcome lies in the third party awards that the final scheme was awarded for quality of the living environment and sustainability criteria deeply embedded in the SPECTRUM list. The completed phase 1, the ICON housing development, won a Building for Life 'Gold Award' from the Commission for Architecture and the Built Environment and attained the highest score ever awarded and a BREEAM 'Excellent' rating for the environmental performance of the buildings and space. It was also overall winner of the 2010 Housing Design Awards ${ }^{1}$ and the participatory process came in for specific praise. It is also worth noting that the criteria used to judge these awards closely align to the original 22 SPECTRUM grading criteria developed for the site.

The focus of this paper has been the degree to which the deliberate omission of criteria weighting is an essential factor in the technique's effectiveness. With SPECTRUM, the lack of weighting supported inclusivity through engaging people in an open and creative grading experience. This in turn helped maintain the rationality whilst allowing critical discourse that conventional appraisal approaches often struggle to provide.

The relationships between HIA and SEA are still unclear and there are calls for various forms of Integrated Appraisal, for example combining EIA and HIA into one process. Whatever appraisal system is used it needs to be 'fit for purpose'. Specific attributes can be derived from the theory but are rarely found in practice. At the local level, sustainability and health both arrive with strong value-laden baggage. Weighting is not useful in a value-based debate where different agencies and community stakeholders have very different priorities and individual goals become submerged within the process 
of summation. Values themselves need to be kept open to challenge and review, as subsequent data and opinions are aired in pursuit of the best outcome. SPECTRUM does not in itself replace other tools - it can act in their absence and is equally of value in adding to an inclusive process in which EIA or HIA data can be examined. As such, in revisiting, we find that the four challenges for integrating rational appraisal with participation have been satisfied:

How can the inequality of participants (and especially non-participants) in the process be addressed in a defensible manner? Grading the criteria, in the absence of weighting, allows participants to address all criteria on an equal basis. Notional non-participants, such as biodiversity or specific global communities, are also dealt with on this basis. This encourages an atmosphere to prevail where, when grading, all participants give equal consideration to each of the issues that they have agreed to address in the earlier criteria setting stage. No stakeholder feels marginalised or antagonised because their particular interest receives a low weight.

How can the diversity of measuring rods used to assess impact (financial, physical, public attitudes etc) be accommodated? Since there is no ultimate single score for the evaluation, but a spectrum of colours, each impact can be measured in the unit which most suits its nature, finance for the more economically driven criteria and say, the area of target habitat created for biodiversity. Complicated, and inevitable socially constructed, and hence value laden, conversion techniques are not required.

How can an evidence-based approach avoid resulting in a narrow reductionism that can also be impermeable to the community? Lay participants and participants representing non-technocratic constituencies, find the grading of each criterion on its own basis easy to grasp. They can supply local knowledge and evidence, which can be recorded in parallel with professional judgements and evidence from technical reports. As there is no weighting or the reduction to a single unitary base, different forms of qualitative and quantitative data are kept visible and do not need to be subsumed by numeric indicators in the final stages.

How can conflict resolution and synergistic policy development be achieved? In the absence of weighting and the associated adding up of scores, each criterion stands alone to be optimised. The approach encourages consensus-building actions. To achieve a better overall grading profile, each participant needs to scan the criteria list and look for synergies, everyone in the group is empowered to identify options for mutual gain.

In the ICON case study, SPECTRUM supported an appraisal process that allowed the design team to use their creativity and find synergy between criteria resulting in an award winning solution. Experience in running SPECTRUM appraisal shows that potentially intractable tensions may be eased through careful handling the concerns of prospective dissenting voices, allowing them into a strongly bounded but inclusive appraisal process. The absence of weighting is an essential feature in these outcomes. 


\section{Concluding thoughts}

Since the application of SPECTRUM to the ICON proposal, the technique has been developed further to explicitly include the wider determinates of health and to include assessment of health inequalities. The approach has been flexibly adapted to suit wider applications such as inclusion of political members, rapid expert group appraisal and policy appraisal. The next stage of development for SPECTRUM, already entered into, is supporting other groups to initiate and facilitate the process supported by, but at arm's length from, the WHO Collaborating Centre for Healthy Urban Environments.

Through placing value-focussed but critical thinking firmly on the agenda, SPECTRUM has the ability to position participatory analysis centrally within local planning and support the kinds of dialogues necessary for successful outcomes. One of its many strengths is to shift project deliberations from a rigid 'positions focus' to a more flexible 'solutions focus'. With the advent of what could be the localism turn within spatial planning, SPECTRUM could be of immense value in securing both rationality and inclusivity in the neighbourhood arena.

\section{Explanatory Note}

1. This award is promoted by Communities and Local Government, NHBC, RIBA, the Royal Town Planning Institute, Homes and Communities Agency, the Royal Institution of Chartered Surveyors, the London Development Agency and the Department of Health 


\section{References}

Allmendinger, P. and Haughton, G., 2007. The fluid scales and scope of UK spatial planning, Environment and Planning A, 39 (6), 1478-1496.

Allmendinger, P. and Haughton, G., 2009. Critical reflections on spatial planning. Environment and Planning A, 41(11) 2544-2549.

Barker, T., 2008. The economics of avoiding dangerous climate change. An editorial essay on The Stern Review. Climatic Change, 89, 173-194.

Barton H., Gray S., Lease H., Carmichael L. and Pilkington P., 2011. Spatial planning and health: integrating health into the planning process Review 5/6. London: NICE.

Barton, H.,1995. The Capacity to Deceive. ECOS, 16 (4).

Barton, H. and Grant, M., 2006. A health map for the local human habitat. The Journal of the Royal Society for the Promotion of Health, 126 (6), 252-253.

Barton, H. and Grant, M., 2008. Testing time for health and sustainability. The Journal of the Royal Society for the Promotion of Health, 128 (3), 130-139.

Barton, H., Grant, M. and Guise, R., 2010. Shaping Neighbourhoods for local health and global sustainability. London: Routledge.

Bazerman, M. H., 1998. Judgment in Managerial Decision-making, 4th ed. New York: John Wiley.

Berger, P. L. and Luckmann, T., 1971. The social construction of reality: A treatise in the sociology of knowledge. Harmondsworth: Penguin.

Bojorquez-Tapia, L.A., Sanchez-Colon, S., Martinez, A.F., 2005. Building consensus in environmental impact assessment through multicriteria modeling and sensitivity analysis. Environmental Management 36 (3), 469-481.

Brown V. A., Grootjans J, Ritchie J, Townsend M, and Verrinder G., 2005.

Sustainability and health. London: Earthscan

Carroll, B., Barton, H., Doidge, C. and Turpin, T., 2002. Sustainability Thresholds Analysis: and approach to inform decision-making: Summary Guidance for Agency staff. London: Environment Agency.

Chambers, R., 1994. The origins and practice of participatory rural appraisal, World Development, 22 (7), 953-969.

Chapin, S., 1965. Land use planning, second edition. Illinois: Urbana, University of Illinois Press.

CLG, 2009. Multi-criteria analysis: a manual. Wetherby: Communities and Local Government Publications.

CLG, 2011. Draft National Planning Policy Framework, Wetherby: Communities and Local Government Publications. 
Cox J., Fell D. and Thurstain-Goodwin M., 2002. Red Man, Green Man, London: RICS Foundation.

DEFRA, 2005. Securing the Future: The UK Government Sustainable Development Strategy. Norwich:TSO

DEFRA, 2011. Mainstreaming sustainable development - The Government's vision and what this means in practice. Available online

http://sd.defra.gov.uk/documents/mainstreaming-sustainable-development.pdf [accessed 8 march 2012]

Devuyst, D., 2000. Linking impact assessment and sustainable development at the local level: The introduction of sustainability assessment systems. Sustainable development, 8 (2), 67-78.

DH, 2007. Draft guidance on health in strategic environmental assessment: consultation document. London: Department of Health.

DH, 2012. Healthy lives, healthy people: Improving outcomes and supporting transparency: Part 1: A public health outcomes framework for England, 2013-2016, Available online

http://www.dh.gov.uk/en/Publicationsandstatistics/Publications/PublicationsPolicyAnd Guidance/DH_132358, [accessed 26.01.2012]

EEA, 2006. Urban sprawl in Europe: The ignored challenge. Copenhagen: European Environment Agency.

EEA, 2006. Ensuring quality of life in Europe's cities and towns. Copenhagen:

European Environment Agency.

Falludi, A., 1973. Planning theory. Oxford: Pergamon.

Figueira, J., Greco, S. and Ehrgott, M., 2005. Multiple criteria decision analysis: state of the art surveys, Boston: Kluwer Academic Publishers.

Fiorino, D., 1989. Environmental risk and democratic process: a critical review. Columbia Journal of Environmental Law, 14, 501-547.

Forester, J., 1989. Planning in the face of power. University of California Press: Berkeley.

Frasera, E. D. G., Dougilla, A. J., Mabeeb, W. E., Reeda, M. and McAlpinec, P., 2006. Bottom up and top down: Analysis of participatory processes for sustainability indicator identification as a pathway to community empowerment and sustainable environmental management. Journal of Environmental Management, 78 (2), 114-127.

Gibbons, M., Limoges, C., Nowotny, H., Schwartzman, S., Scott, P. and Trow, M., 1994. The new production of knowledge : the dynamics of science and research in contemporary societies. London: Sage.

Goodstadt V., 2009. Working across boundaries. Town and Country Planning 78(3) 8. 
Grant, M., 2003. Involving the community in selecting indicators: The UK case study, Bristol. In: Mobility, Urban Planning and Sustainable Development Strategies for Neighbourhood Renovation, HQE2R International Workshop, 8th-9th September, Mantova, Italy.

Grant, M., 2004. Innovation in tourism planning processes: Action learning to support a coalition of stakeholders for sustainability. Tourism and Hospitality Planning \& Development, 1 (3), 219-237.

Gregory, R., 2000. Using stakeholder values to make smarter environmental decisions, Environment. Science and Policy for sustainable development, 42 (5) 34-44.

McGuirk, P. M., 2001. Situating communicative planning theory: context, power and knowledge. Environment and Planning A, 33, 195-217.

Habermas, J., 1981. The Theory of Communicative Action. Boston: Beacon Press.

Habermas, J., 1984. The Theory of Communicative Action-Reason and the Rationalization of Society. Boston: Beacon Press.

Hajkowicz, S., 2008. Supporting multi-stakeholder environmental decisions. Journal of Environmental Management, 88, 607-614.

Hämäläinen, R. P., Alaja, S., 2008. The threat of weighting biases in environmental decision analysis. Ecological Economics, 68, 1-2, 556-569.

Localism Act 2010. London: TSO

Healey, P., 2003. Collaborative Planning in Perspective, Planning Theory, 2 (2), 101123.

Healey, P., 1996. The communicative turn in planning theory and its implications for spatial strategy formations. Environment and Planning B: Planning and Design, 23(2), 217-234.

Healey, P., 1992. Planning through debate: the communicative turn in planning theory. Town Planning Review, 63 (2), 143-162.

Hersh, M.A., 1999. Sustainable Decision Making: The Role of Decision Support Systems . IEEE transactions on systems, man, and cybernetics - Part c: applications and reviews, 29 (3), 395-408.

Innes, J.E., 1998. Information in communicative planning. Journal of the American Planning Association. 64, 52-63.

Khakee, A., 1998. The communicative turn in planning and evaluation, in Lichfield, N., Evaluation in planning: facing the challenge of complexity, Dordrecht: Kluwer

Academic

Kozlowski, J., Hughes, J. T., Brown, R., 1972. Threshold Analysis. London:

Architectural Press. 
Kozlowski, J., Hill G. (Eds.), 1993. Towards planning for sustainable development. Aldershot: Avebury/Ashgate Publishing

LUC and RTPI, 2008. Issues for the practice of sustainability appraisal in spatial planning - a review: final report. Prepared for the Sustainable Development Research Network as part of the Spatial Planning Workstream, London: Land Use Consultants.

Malisz, B., 1972. Threshold analysis as a tool in urban and regional planning. Papers in Regional Science, Volume 29, Issue 1, pages 167-177.

McGuirk, P. M., 2001.Situating communicative planning theory: context, power, and knowledge. Environment and Planning A. 33 (2) 195-217.

McLoughlin, B., 1968. Urban and regional planning: a systems approach. London: Faber.

Munda, G., 2005. Measuring Sustainability: A Multi-Criterion Framework, Environment, Development and Sustainability, 7(1), 117-134.

Munda, G., 2008. Social multi-criteria evaluation for a sustainable economy. Berlin: Spinger-Verlag.

Nadin, V., 2006. The Role and Scope of Spatial Planning, [on-line] Available from: http://www.communities.gov.uk/documents/planningandbuilding/pdf/rolespatialplannin g.pdf [accessed July 14 2010].

Nadin, V., 2007. The emergence of the spatial planning approach in England. Planning Practice and Research 22,1.

NICE, 2008. Promoting and creating built or natural environment that encourage and support physical activity, NICE public health guidance 8. London: NHS.

Nowotny, H. et al., 2001. Rethinking Science; Knowledge and the Public in an Age of Uncertainty. Cambridge: Polity Press.

POS, 2005. Planning officers society Meeting Notes 26/04/05 [online]. Planning Officers Society. Available from: http://www.planningofficers.org.uk/POS-SupportedLearning-Groups/LDF-Learning-and-Dissemination-Project/Meeting-Notes-260405/ [Accessed 13 September 2011].

Posas, P. J., 2011. The UK’s Draft Guidance for Heath in SEA in light of community priorities and the UNECE SEA Protocol. Environmental Assessment Review, 31, 320327.

Poston, A., Emmanuel, R. and Thomson, C., 2010. Developing holistic frameworks for the next generation of sustainability assessment methods for the built environment. In: C. Egbu, ed. Procs $26^{\text {th }}$ Annual ARCOM Conference, 6-8 September 2010, Leeds. UK: Association of Researchers in Construction Management, 1487-1496.

Rittle, H. W. J. and Webber, M. M., 1973. Dilemmas in a General Theory of Planning. Policy Sciences, 4 , 155-169. 
RCEP, 2002. Environmental Planning. London: Royal Commission on Environmental Pollution.

RPA, 2000. Comprehensive project appraisal: Towards sustainability. London: Royal Institute of Chartered Surveyors

Skollerhorn, E., 1998. Habermas and nature: The theory of communicative action for studying environmental policy. Journal of Environmental Planning \& Management, 41, 555-573.

Slovic, P. Fischhoff, B. and Lichenstein, S., 1977. Behavioural decision theory. Annual review of Psychology, 28, 1-39.

Stern, N., 2007. The economics of climate change: The Stern Review. Cambridge:

Cambridge University Press.

Strategic Solutions, 2010. Study of local planning process and health. London: NICE.

Taylor, N., 1998. Urban planning theory since 1945. London: Sage.

The Planning and Compulsory Purchase Act 2004. London: TSO.

Thomson, C. S., El-Haram, M. and Hardcastle, C., 2009. Managing knowledge of urban sustainability assessment. Proceedings of the Institution of Civil Engineers, Engineering Sustainability, 162 (ES1), 35-43.

Tonn, B., English, M. and Travis, C., 2000. A Framework for understanding and improving environmental decision making. Journal of Environmental Planning \& Management, 43 (2), 163-183.

WHO, 1997a City planning for health and sustainable development: European Sustainable Development and Health Series: 2. Copenhagen: WHO Regional Office for Europe.

WHO, 1997b. Sustainable development and health: Concepts, principles and framework for action for European cities and towns European Sustainable Development and Health Series : Book 1. Copenhagen: WHO Regional Office for Europe.

WHO, 2009. Zagreb Declaration for Healthy Cities. WHO Regional Office for Europe Wong, C. and Watkins, C., 2009. Conceptualising Spatial Planning Outcomes: towards an integrative measurement framework. Town Planning Review, 80 (4/5), 481-516. 